\title{
US health insurance companies screen applicants for AIDS
}

Washington

US health insurance companies are now routinely screening individual health insurance applicants for AIDS (acquired immune deficiency syndrome), according to a new report* from the congressional Office of Technology Assessment (OTA). The change has occurred without a national consensus on how those refused insurance should be helped, or on how an individual's level of risk of exposure to AIDS can be fairly assessed.

The number of people seeking individual health insurance is less than 10 per cent of the total insured population, and of this percentage half are elderly people who are unlikely to contract AIDS. It is the remaining half, made up of around 5 million individuals, that is causing concern to companies specializing in individual insurance. Most Americans are covered under group health insurance plans at work. These plans apply to sufficiently large numbers of people to cope with the few who will develop AIDS.

The insurance companies say that they must protect themselves financially by refusing insurance to those at risk from AIDS, just as they refuse insurance to those likely to suffer from cancer, coronary heart disease and mental illness.

But ethical problems remain over assessing a person's risk from AIDS, with homosexuals' activist groups arguing that homosexuality, which can place a person in a higher risk group for AIDS, cannot be regarded in the same way as smoking, which places someone in a higher risk group for cancer.

California and Washington, DC, have gone to the extreme of passing laws prohibiting the use of AIDS tests by insurers. Washington, DC, also bars companies from asking for medical information that might be used to assess a person's exposure to the AIDS virus. Insurance companies object strongly to these restrictions.

Most insurance companies do, however, agree that sexual orientation should not be a factor in underwriting. The National Association of Insurance Commissioners specifically advises state governments to forbid the practice. But according to the OTA report, 30 per cent of insurance companies take sexual orientation into account. Other companies ask applicants if they have suffered from sexually transmitted diseases common among promiscuous homosexuals. Tests for exposure to the HIV virus which causes AIDS are becoming commonplace. Half the insurance companies routinely test for HIV antibodies.

As the impact of the AIDS epidemic grows, companies insuring individuals will become stricter, according to the report. HIV-antibody testing will be expanded and more AIDS-related questions added to applications. Companies are also more likely to examine AIDS cases to see if they can be linked to a pre-existing condition that would reduce liability. An insurance association survey has already shown that most AIDS-related claims are in the first two years after coverage begins, suggesting that individuals suspected that they were infected when they purchased insurance.

The Public Health Service has estimated that the cost of health care for AIDS patients will rise to between $\$ 8,000$ million and $\$ 16,000$ million dollars by 1991. As the epidemic spreads, there will be increasing pressure on state schemes which provide help for those who carnnot obtain personal insurance. These rely on contributions taken from insurance company income. Insurance companies are calling for federal legislation to spread the burden wider.

Alun Anderson *AIDS and Health Insurance: An OTA survey, February 1988

\section{Easier access to UK defence labs London}

THE British government this week announced a new scheme to allow civil industry increased access to four Ministry of Defence (MoD) research establishments. The Civil Industrial Access Scheme (CIAS) is a joint initiative of the MoD and the Department of Trade and Industry. Industrial users of the establishments will be charged market rates for the use of facilities and for consultations with MoD staff.

Launching the scheme, trade minister John Butcher said he was confident that the venture would help strengthen the research arm of British industry. Butcher expects the scheme to be of particular interest to small- and medium-sized companies that connot afford to invest in expensive equipment and facilities.

CIAS is part of the MoD's drive in recent years to exploit more fully research it undertakes. The establishments already carry out some civil work, mostly in aerospace and electronics - commercial spinoffs from defence work are exploited by a company recently set up by the MoD, Defence Technology Enterprises Ltd.

The new scheme will operate in the Admiralty Research Establishment, Royal Aircraft Establishment, Royal Armament Research and Development Establishment and the Royal Signals and Radar Establishment. Simon Hadlington

\section{New supercon- ductor magnets}

\section{Washington}

THE new high critical temperature $\left(T_{c}\right)$ ceramic superconductors could, in principle, be used to build the magnets for the Superconducting Super Collider (SSC), but a US Department of Energy (DoE) report* concludes that it will take at least 12 years to overcome the "formidable materials science and engineering problems" of the new materials.

The flurry of excitement last year over the new class of superconducting compounds prompted $\mathrm{DoE}$ to investigate their use as SSC magnets. In requesting the investigation, Alvin Trivelpiece, then director of the Office of Energy Research, admitted that the task was not easy, "considering the rapidity with which the science is developing", a point driven home by the discovery of bismuth-calcium superconductors (see Nature 331, 377; 1988).

A panel chaired by Albert Narath of AT\&T Bell Laboratories has now determined that further development of the rare-earth oxides would achieve the $10^{5}$ $\mathrm{A} \mathrm{cm}{ }^{-2}$ critical current and $7 \mathrm{~T}$ critical magnetic field required to operate the SSC.

But the stringent performance requirements of accelerator magnets demand huge strides in materials processing before the new materials could even be considered for use in SSC. Under "optimistic conditions", the panel reckons it would take 4 years to develop processes to make continuous lengths of $5-10-\mu \mathrm{m}$ diameter superconducting wire with appropriate mechanical properties. Another 8 years would be needed to develop winding techniques for building prototype magnets.

It is also not simply a matter of exchanging yttrium-barium-copper oxide superconducting wire for the niobium-titanium wire used in current designs. The new materials have higher heat capacity, making it necessary to add active magnet protection in case of accidental loss of superconducting properties.

Other design features would have to be modified to use liquid-nitrogen cooling for SSC. Operating at $77 \mathrm{~K}$, rather than $4 \mathrm{~K}$, requires higher vacuums and larger magnet aperture modifications that could offset any savings from operating at the higher temperature.

Experience with niobium-tin superconductors underscores the trade-offs between materials with desirable electrical and magnetic properties, but poor mechanical properties. Niobium-tin wires have been available for 20 years, but are too brittle. Joseph Palca

${ }^{*}$ Report of the Basic Energy Sciences Advisory Committee panel on high- $T_{\mathrm{c}}$ superconducting magnet applications in particle physics, US Department of Energy, Office of Energy Research, Washington, DC, 1987. 